\title{
Spasm Provocation Tests under Medication May Help Decide on Medical or Mechanical Therapy in Patients with Aborted Sudden Cardiac Death due to Coronary Spasm
}

\author{
Shozo Sueda, Tomoki Sakaue and Takafumi Okura
}

\begin{abstract}
:
Objective The decision to perform medical or mechanical therapy in patients with aborted sudden cardiac death (ASCD) due to coronary spasm is controversial. The Japanese Circulation Society guidelines for the diagnosis and treatment of patients with coronary spastic angina mentioned that implantable cardioverterdefibrillator (ICD) is one option in patients with ASCD due to coronary spasm. We investigated the usefulness of spasm provocation tests under medications in five patients with ASCD due to coronary spasm.

Methods We performed the spasm provocation tests under medications in five ASCD patients due to coronary spasm. Pharmacological spasm provocation tests, including five acetylcholine (ACh) tests, two ergonovine (ER) tests, and two ACh added after ER tests, were performed to estimate the effect of medications to suppressing the next fatal spasms.

Results ACh tests under medications did not provoke spasm in one patient but did provoke in two patients. In the remaining two patients, neither the ACh test nor the ER test provoked spasm, but the ACh added after ER test induced a focal spasm in one coronary artery. We increased the medication dosage in four patients. An ICD was implanted in two patients, including one with refractory spasm and one with left main trunk spasm. One patient died due to pulseless electrical activity without ventricular fibrillation, while the remaining four patients survived.

Conclusion Spasm provocation tests under medication in patients with ASCD due to coronary spasm may be an option when deciding on medical or mechanical therapy.
\end{abstract}

Key words: ventricular fibrillation, coronary artery spasm, implantable cardioverter-defibrillator, aborted sudden cardiac death, medications

(Intern Med 59: 1351-1359, 2020)

(DOI: 10.2169/internalmedicine.4158-19)

\section{Introduction}

In 1986, intracoronary acetylcholine (ACh) testing was first reported by Yasue et al. (1). Since then, intracoronary ACh test has become popular as a spasm provocation test worldwide, as has the ergonovine (ER) test (2-6). We previously reported the usefulness of sequential spasm provocation tests in the clinic in 2000 (7). Single spasm provocation test, such as the ACh test or ER test alone, may fail to detect clinical everyday spasm in the cardiac catheterization laboratory. Sequential spasm provocation tests may therefore be extremely powerful spasm provocation tests (8). According to the Japanese Circulation Society (JCS) guidelines for the diagnosis and treatment of patients with coronary spastic angina (CSA), cessation of vasodilators for more than $48 \mathrm{~h}$ before the spasm provocation tests is recommended (9).

We have experienced patients with aborted sudden cardiac death (ASCD) due to pure coronary artery spasm in the clinic. The JCS guidelines mentioned an implantable cardioverter-defibrillator (ICD) as a treatment option for these patients (9), and this device was inserted in some patients $(10,11)$, while aggressive medication without ICD implantation was performed in other patients. However, the de- 
Table 1. Clinical Findings in 5 Patients with Aborted Sudden Cardiac Death Due to Coronary Spasm.

\begin{tabular}{|c|c|c|c|c|c|c|c|c|c|c|c|}
\hline No & Age & Sex & Diagnosis & Risk factor & $\begin{array}{c}\text { Duration } \\
\text { (month) }\end{array}$ & $\begin{array}{l}\text { Organic } \\
\text { stenosis }\end{array}$ & OMI & $\mathrm{EF}$ & ICD & Prognosis & Before medication \\
\hline 1 & 68 & M & $\mathrm{VF}$ & C smoker & 52 & no & yes & $42 \%$ & no & alive & Carvedilol $2.5 \mathrm{mg}$ \\
\hline 2 & 52 & M & $\mathrm{VF}$ & $\mathrm{C}$ smoker/HT & 11 & $\# 7(50 \%)$ & no & $78 \%$ & yes & alive & Terumisartan $40 \mathrm{mg}$ \\
\hline 3 & 59 & M & VF & C smoker/HT/DL & 128 & no & no & $72 \%$ & no & alive & Amlodipine $5 \mathrm{mg}$ \\
\hline 4 & 73 & M & VF & NC smoker/DM/DL & 126 & no & no & $75 \%$ & no & alive & Amlodipine $5 \mathrm{mg}$ \\
\hline 5 & 61 & M & VF & C smoker & 15 & no & no & $78 \%$ & yes & dead & none \\
\hline
\end{tabular}

OMI: old myocardial infarction, EF: ejection fraction by ultrasonography, ICD: implantable cardioverter-defibrillator, M: male, VF: ventricular fibrillation, C: current, NC: non-current, HT: hypertension, DM: diabetes mellitus, DL: dyslipidemia

Table 2. Spasm Provocation Tests under Medications in 5 Patients with Aborted Sudden Cardiac Death Due to Coronary Spasm.

\begin{tabular}{|c|c|c|c|}
\hline No & $\begin{array}{l}\text { Spontaneous spasm or } \\
\text { ST change }\end{array}$ & Spasm provocation test without medication & Spasm provocation test under medications \\
\hline 1 & ST ele in ANT & $\begin{array}{l}\text { ACh (L:50) \#6 (total) \#11 (diffuse) } \\
\text { ACh (R:20) \#3 (total) }\end{array}$ & $\begin{array}{l}\text { ACh (L:20/50/100/200) no spasm } \\
\text { ACh (R:20/50/80) no spasm } \\
\text { ER (L:64) no spasm } \\
\text { ER (R:40) no spasm } \\
\text { ACh (L:200) after ER (64) no spasm } \\
\text { ACh (80) after ER (40) \#3 (focal) }\end{array}$ \\
\hline 2 & $(-)$ & $\begin{array}{l}\text { ACh (L:20) \#5 (focal) \#7 (focal) } \\
\text { ACh (R:20) \#4 (diffuse) after nitroglycerine } 0.1 \mathrm{mg} \text { in LCA }\end{array}$ & $\begin{array}{l}\text { ACh (L:20/50/100/200) no spasm } \\
\text { ACh (R:50/80) no spasm } \\
\text { ER (L:64) no spasm } \\
\text { ER (R:40) no spasm } \\
\text { ACh (200) after ER (64) \#7 (focal) } \\
\text { ACh (R:80) after ER (40) no spasm }\end{array}$ \\
\hline 3 & ST ele in INF \& ANT & $(-)$ & $\begin{array}{l}\text { ACh (L:50/100) no spasm } \\
\text { ACh (R:50) no spasm }\end{array}$ \\
\hline 4 & Negative $\mathrm{T}$ in ANT & $\begin{array}{l}\text { ACh (L:25) \#7 (diffuse) \#11 (diffuse) } \\
\text { ACh (R:25) \#2 (total) }\end{array}$ & $\begin{array}{l}\text { ACh (L:25/50/100) \#8 (focal) \#13 (diffuse) } \\
\text { ACh (R:25) \#2 (focal) }\end{array}$ \\
\hline 5 & $(-)$ & $\begin{array}{l}\text { ACh (L:20) \#6 (diffuse) \#11 (diffuse) } \\
\text { ACh (R:20) \#1 (subtotal) }\end{array}$ & $\begin{array}{l}\text { ACh (L:50/100) \#6 (diffuse) \#11 (diffuse) } \\
\text { ACh }(20 / 50 / 80) \# 4 \text { AV (total) }\end{array}$ \\
\hline
\end{tabular}

ACh: acetylcholine, ER: ergonovine, R: right coronary artery, L: left coronary artery

cision to perform medical or mechanical therapy in patients with ASCD due to coronary spasm is controversial, and at present, cardiologists have no way to identify those patients who would most benefit from an ICD.

We herein report the results of spasm provocation tests under the medication in five ASCD patients due to coronary spasm.

\section{Materials and Methods}

We recruited five patients with ASCD due to coronary spasm who had undergone spasm provocation tests under medications. All five patients were ventricular fibrillation (VF) survivors, as shown in Table 1. The spasm provocation data are shown in Table 2, and the total doses of precise vasodilators, including calcium channel blockers, are shown in Table 3. We have already reported three cases (case 2, 3, and 4) $(12,13)$.

The study protocol complied with the Declaration of Helsinki. Written informed consent was obtained from all pa- tients before performing the pharmacological spasm provocation tests, and the protocol of this study was in agreement with the guidelines of the ethical committee at our institution.

\section{Statistical analyses}

Data analyses were performed using the SPSS software program (version 22.0, IBM Japan, Tokyo, Japan). All data were presented as the median (minimum, maximum) and were analyzed by Fisher's exact test with correction or the Mann-Whitney U test. $\mathrm{p}<0.05$ was considered significant.

\section{Case 1}

A 68-year-old man was taken to our hospital via ambulance because of resistant VF. Self-sinus rhythm was obtained by direct current after the administration of amiodarone hydrochloride anti-arrhythmic agents, as shown in Fig. 1A, B. Cardiopulmonary support was continued for approximately 25 minutes. Although coronary arteriography (CAG) was performed because of ST segment elevation in 
Table 3. Medications in 5 Patients with Aborted Sudden Cardiac Death Due to Coronary Spasm.

\begin{tabular}{|c|c|c|c|c|c|c|}
\hline No & $\begin{array}{l}\text { Vasodilators } \\
\text { on admission }\end{array}$ & $\begin{array}{l}\text { Number } \\
\text { of CCB }\end{array}$ & $\begin{array}{l}\text { Vasodilators after the initial spasm } \\
\text { provocation tests }\end{array}$ & $\begin{array}{l}\text { Number of } \\
\text { CCB }\end{array}$ & $\begin{array}{l}\text { Vasodilators after the spasm provocation } \\
\text { tests under medications }\end{array}$ & $\begin{array}{l}\text { Number } \\
\text { of CCB }\end{array}$ \\
\hline 1 & 0 & 0 & $\begin{array}{c}3 \text { (Dil-R } 200 \mathrm{mg} / \text { Beni } 8 \mathrm{mg} \text {, ISMN } \\
40 \mathrm{mg} \text { ) }\end{array}$ & 2 & $\begin{array}{l}4 \text { (Dil-R } 200 \text { mg/Beni } 8 \text { mg, ISMN } 40 \text { mg/ } \\
\text { Nico } 15 \text { mg) statin }\end{array}$ & 2 \\
\hline 2 & 0 & 0 & $\begin{array}{l}4 \text { (Dil-R } 200 \mathrm{mg} / \mathrm{Nif}-\mathrm{R} 80 \mathrm{mg} / \mathrm{ISMN} \\
40 \mathrm{mg} / \text { Nit-tape } 40 \mathrm{mg} \text { ) }\end{array}$ & 2 & $\begin{array}{c}4 \text { (Dil-R } 200 \mathrm{mg} / \mathrm{Nif}-\mathrm{R} 80 \mathrm{mg} / \mathrm{ISMN} 40 \\
\mathrm{mg} / \text { Nit-tape } 40 \mathrm{mg} \text { ) statin }\end{array}$ & 2 \\
\hline 3 & 1 (Amlo $5 \mathrm{mg}$ ) & 1 & 2 (Dil-R 100 mg/Amlo 5 mg) & 2 & $\begin{array}{c}4 \text { (Dil-R } 200 \mathrm{mg} / \text { Beni } 8 \text { mg/ISMN } 40 \text { mg/ } \\
\text { Nita-tape } 40 \text { mg) statin }\end{array}$ & 2 \\
\hline 4 & 1 (Amlo $5 \mathrm{mg}$ ) & 1 & 2 (Amlo $5 \mathrm{mg} / \mathrm{ISMN} 40 \mathrm{mg}$ ) statin & 1 & $\begin{array}{l}5 \text { (Dil-R } 200 \mathrm{mg} / \text { Beni } 8 \mathrm{mg} / \mathrm{ISMN} 40 \mathrm{mg} / \\
\quad \text { Nico } 15 \mathrm{mg} / \text { Nit-tape } 40 \mathrm{mg} \text { ) statin }\end{array}$ & 2 \\
\hline 5 & 0 & 0 & 2 (Beni 8 mg/ISMN 40 mg) & 1 & $\begin{array}{c}4 \text { (Beni } 8 \text { mg/Dil-R } 200 \text { mg/ISMN } 40 \text { mg/ } \\
\text { Nico } 15 \text { mg) statin }\end{array}$ & 2 \\
\hline Mean no & $0.4(0-1)$ & $0.4(0-1)$ & $2.6(2-4) *$ & $1.6(1-2)^{*}$ & $4.2(4-5)^{* * \#}$ & $2.0(2)^{*}$ \\
\hline
\end{tabular}

*: $\mathrm{p}<0.01 \& * *: \mathrm{p}<0.001 \mathrm{vs.}$ before admission, \#: $\mathrm{p}<0.05$ vs. initial spasm provocation test, bold type: additional medicine. R: right coronary artery, L: left coronary artery, Amlo: amlodipine, Dil-R: diltiazem R, Beni: benidipine, Nif-R: nifedipine R, ISMN: isosorbide mononitrate, Nico: nicorandil, Nit-tape: nitrate tape, CCB: calcium channel blocker

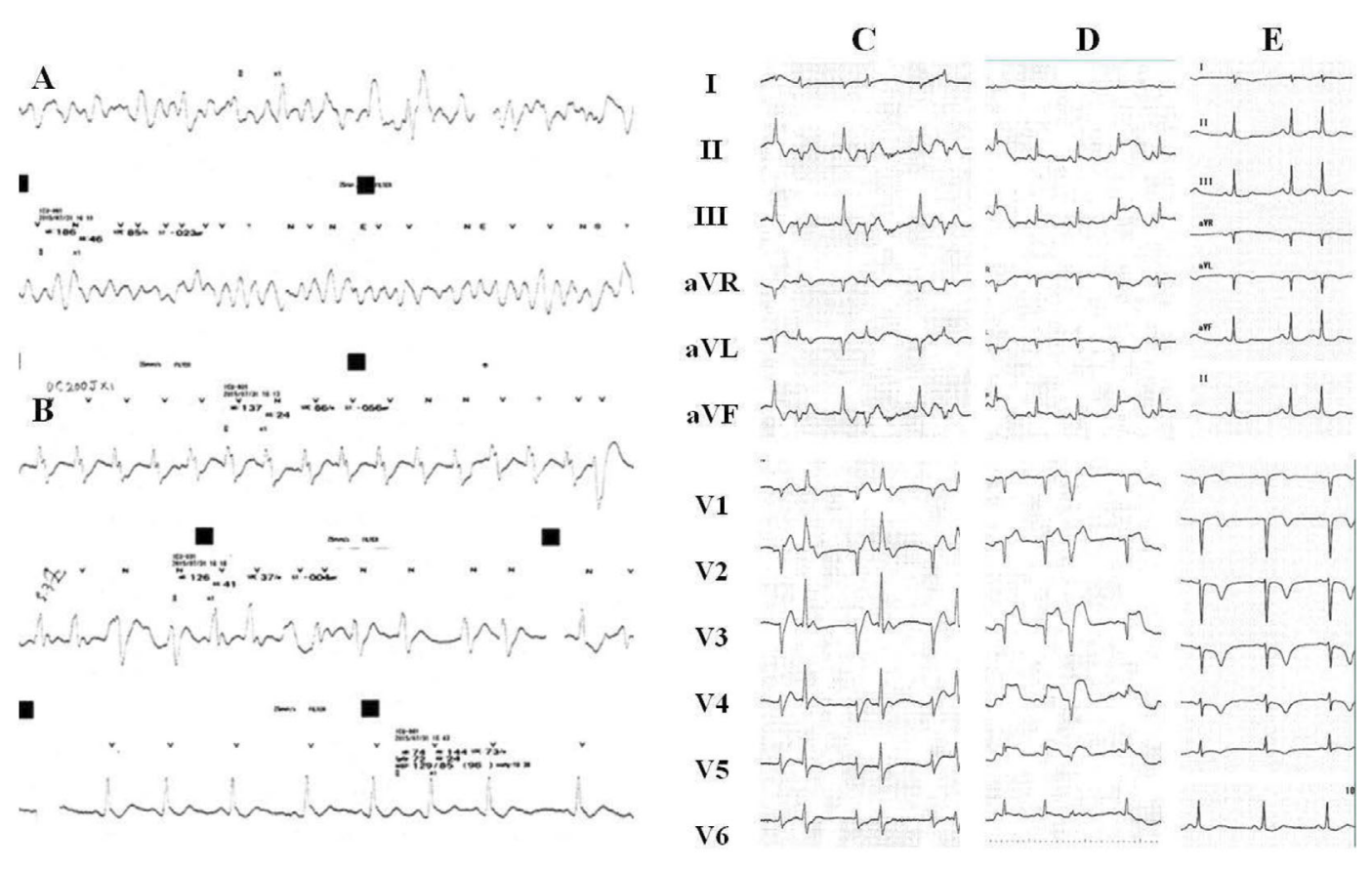

Figure 1. ECG findings. A: ventricular fibrillation on admission. B: after successful defibrillation. C: 12-lead ECG after successful defibrillation. D: 12-lead ECG before emergency CAG. E: 12-lead ECG after 2 days' admission. Ventricular fibrillation was observed on admission (A), and ST-segment elevation in the anterior leads was found after successful defibrillation. (C, D) A negative $T$ wave in the anterior leads was recognized on the day after admission (E). ECG: electrocardiogram

the anterior leads (Fig. 1C, D), no fixed stenosis was found (Fig. 2A, B). He completely recovered without any brain damages with hypothermia therapy and respiratory intubation for three days. Anterior myocardial infarction due to coronary spasm was complicated, and a reduced left ventricular function was observed, as shown in Table 1 . We performed the spasm provocation tests to clarify the presence of coronary artery spasm under no medication. Intracoronary injection of ACh $20 \mu \mathrm{g}$ into the left coronary artery (LCA) documented total spasm at proximal left anterior descending (LAD) artery and diffuse spasm at the left circumflex artery
(LCX), as shown in Fig. 2C, E. We administered nitrate (0.1 $\mathrm{mg}$ nitroglycerine) into the LCA to relieve refractory spasm 4 minutes later. Intracoronary injection of $50 \mu \mathrm{g}$ ACh into the right coronary artery (RCA) provoked total spasm at the mid RCA, as shown in Fig. 2D, F. We diagnosed him as a VF survivor due to severe coronary spasm. After the administration of multiple vasodilators, including two calcium channel blockers (benidipine hydrochloride $8 \mathrm{mg} / \mathrm{day}$ and diltiazem R $200 \mathrm{mg} /$ day twice a day) and isosorbide mononitrate $40 \mathrm{~m} /$ day twice a day, we performed the sequential spasm provocation tests 3 months later to investi- 

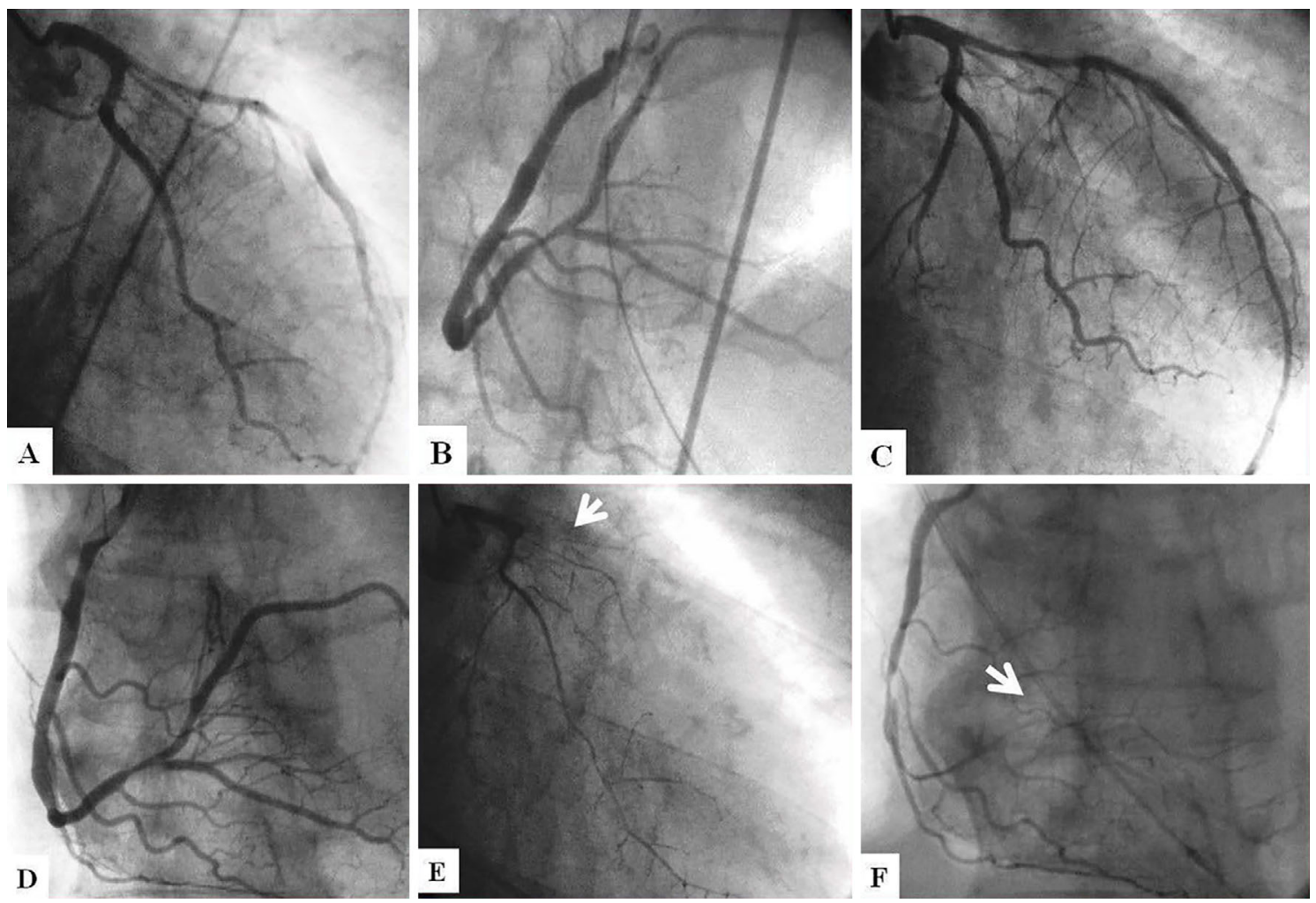

Figure 2. CAG findings on admission and acetylcholine spasm provocation testing. A: LCA on emergency CAG. B: RCA on emergency CAG. C: LCA after the administration of nitrate. D: RCA after the administration of nitrate. E: LCA after the injection of $20 \mu \mathrm{g}$ ACh. F: RCA after the injection of $50 \mu \mathrm{g} \mathrm{ACh}$. No significant stenosis was found on emergency CAG (A, B). Under no medication prior to $24 \mathrm{~h}$, intracoronary injection of $20 \mu \mathrm{g}$ ACh provoked total spasm at proximal LAD and diffuse spasm on LCX (E). After the administration of nitroglycerine $0.1 \mathrm{mg}$ into the LCA, the intracoronary injection of $50 \mu \mathrm{g}$ ACh provoked total spasm at the mid RCA (F). After the administration of nitrates, neither coronary arteries had any fixed stenosis (C, D). CAG: coronary arteriography, LCA: left coronary artery, RCA: right coronary artery, LAD: left anterior descending artery, LCX: left circumflex artery, ACh: acetylcholine

gate whether or not the medications suppressed the coronary artery spasm. No provoked spasms were noted on single spasm provocation tests, such as the ACh test and just ER tests alone, as shown in Fig. 3A to F. Adding ACh $200 \mu \mathrm{g}$ after intracoronary ER $64 \mu \mathrm{g}$ into the LCA also provoked no spasm (Fig. 3G), although adding intracoronary $80 \mu \mathrm{g}$ ACh after ER $40 \mu \mathrm{g}$ into the RCA induced diffuse spasm at the mid RCA (Fig. 3H). Nicorandil $15 \mathrm{mg}$ was added to the above medications. The patient refused ICD implantation. He has maintained good control under medications with multiple vasodilators as an outpatient without ICD for 52 months.

\section{Case 2}

A 52-year-old man recovered from VF suffered while jogging leisurely with an automated external defibrillator and cardiac massage by a bystander. He was transferred to our hospital via ambulance. Under intubation with hypothermia therapy, he completely recovered without any irreversible complications. He had had neither chest symptom nor a history of syncope during his daily life for 52 years. We per- formed CAG without premedication on day 10 of admission. His LCA showed moderate stenosis at the left main trunk (LMT) and mid LAD artery. The intracoronary administration of $20 \mu \mathrm{g}$ ACh into the LCA induced a focal spasm at the LMT and mid LAD artery without any chest symptoms or ischemic electrocardiographic changes. After the spontaneous relief of spasm, we administered $20 \mu \mathrm{g}$ ACh into the RCA. Diffuse distal spasm was documented without any chest symptoms or ischemic electrocardiographic changes. After the administration of nitrate, moderate stenosis (50\%) was found at segment 7 . We diagnosed him as a VF survivor due to silent severe multiple coronary spasm including LMT. We administered abundant vasodilators, including 2 calcium channel antagonists (nifedipine CR $80 \mathrm{mg} /$ day and diltiazem R $200 \mathrm{mg} /$ day) and nitrates (isosorbide mononitrate $40 \mathrm{mg} /$ day and nitrate tape $40 \mathrm{mg} /$ day) instead of telmisartan. We decided to implant a subcutaneous-ICD (S-ICD) in this patient because he had silent severe coronary spasm including LMT. After the implantation of S-ICD, we performed the pharmacological spasm provocation tests under the above medications to check whether or not these medi- 

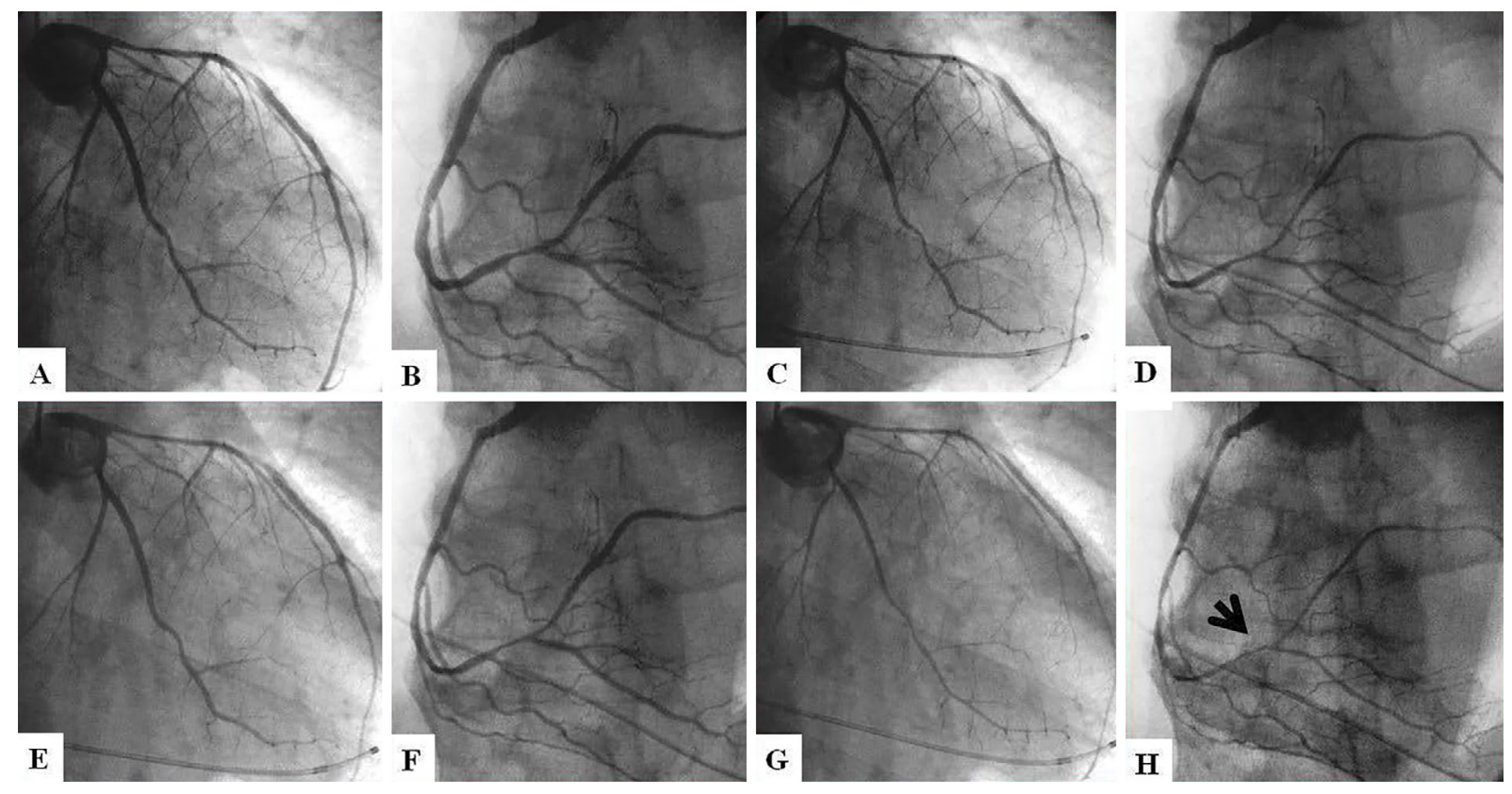

Figure 3. Spasm provocation test findings under sufficient medication. A: LCA after the nitrate. B: RCA after the nitrate. C: LCA after the injection of ACh $200 \mu \mathrm{g}$. D: RCA after the injection of ACh $80 \mu \mathrm{g}$. E: LCA after the administration of ER $64 \mu \mathrm{g}$. F: RCA after the administration of ER $40 \mu \mathrm{g}$. G: LCA after adding ACh $200 \mu$ following ER $64 \mu \mathrm{g}$. H: RCA after adding ACh $80 \mu \mathrm{g}$ following ER 40 $\mu \mathrm{g}$. The intracoronary injection of ACh or ER provoked no spasm in either coronary arteries under sufficient medications (C-F). Adding an intracoronary injection of ACh $200 \mu \mathrm{g}$ after ER $64 \mu \mathrm{g}$ into the LCA also did not provoke spasm (G), whereas adding the intracoronary injection of ACh $80 \mu \mathrm{g}$ after ER $40 \mu \mathrm{g}$ induced diffuse spasm at the mid RCA $(\mathrm{H})$. After the administration of nitrates, neither RCA nor LCA had any significant stenosis (A, B). LCA: left coronary artery, RCA: right coronary artery, ACh: acetylcholine, ER: ergonovine

cations suppressed the LMT spasm. The intracoronary administration of ACh 20/50/100/200 $\mu \mathrm{g}$ into the LCA or 80 $\mu \mathrm{g}$ into the RCA did not induce spasm. Furthermore, the intracoronary injection of ergonovine (ER) $64 \mu \mathrm{g}$ into the LCA or $40 \mu \mathrm{g}$ into the RCA did not result in any coronary vasoconstriction. Adding ACh $200 \mu \mathrm{g}$ after ER $64 \mu \mathrm{g}$ into the LCA induced focal spasm at segment 7 with ischemic ST segment depression in I aVL leads $(1.0 \mathrm{~mm})$ and with no chest symptoms. Adding ACh $80 \mu \mathrm{g}$ after the ER $40 \mu \mathrm{g}$ into the RCA did not induce any spasm. We did not perform percutaneous coronary intervention at segment 7 because of the $50 \%$ stenosis. We believed that this aggressive medication would suppress the next fatal ventricular arrhythmia due to coronary spasm in the future. He was discharged in a good condition on day 28. He had no chest symptoms, syncopal attack or appropriate ICD shocks for 11 months.

\section{Case 3}

A 59-year-old man was admitted to our hospital via ambulance due to severe chest pain without ischemic electrocardiogram (ECG) changes. Emergency CAG was performed, and the patient's RCA showed severe spasms. Following the administration of abundant nitrates into the responsible vessels, both coronary arteries gradually dilated, and no fixed stenosis was recognized. He was diagnosed with CSA and discharged after receiving two calcium- channel blockers (diltiazem R: $100 \mathrm{mg}$ /day before sleep \& amlodipine: $5 \mathrm{mg} /$ day in the morning). Six months later, he was readmitted to our hospital via ambulance due to severe chest pain. His ECG demonstrated ST elevation in the inferior and anterior leads. After several administrations of nitroglycerine, the ST elevation gradually decreased. However, VF occurred, and the patient recovered to a sinus rhythm by the application of direct current. Emergency CAG was performed, and normal coronary angiograms were found. Prior to discharge, a spasm provocation test of ACh was performed under medical therapy including three vasodilators (diltiazem R: $200 \mathrm{mg} /$ day, benidipine: $8 \mathrm{mg} /$ day \& isosorbide mononitrate: $40 \mathrm{mg} /$ day). Intracoronary injection of $100 \mu \mathrm{g}$ ACh into the LCA or $50 \mu \mathrm{g}$ ACh into the RCA provoked no spasm under the medical therapy, and we believed that this therapy would be effective in suppressing the patient's chest pain attacks. For 128 months after the spasm provocation test under medications, this patient has been well except one urgent admission without a hospital stay.

\section{Case 4}

A 72-year-old man was transferred to our hospital via ambulance as a VF survivor. On emergency CAG, no fixed stenosis was detected, despite the presence of negative $T$ changes in anterior leads. Following the administration of a calcium channel blocker (amlodipine: $5 \mathrm{mg}$ /day) and nitrate 
(isosorbide mononitrate: $40 \mathrm{mg} / \mathrm{day}$ ), he complained of no further chest pain. Prior to discharge under no medication, the intracoronary administration of $20 \mu \mathrm{g}$ of ACh provoked 3-vessel spasms consisting of proximal RCA total spasms, mid-LAD diffuse spasms, and proximal-LCX diffuse spasms. Approximately four months later, he was readmitted to our hospital via ambulance due to recurrent chest pain attacks. We administered another vasodilator including diltiazem R $200 \mathrm{mg} /$ day and nicorandil $15 \mathrm{mg} /$ day. Under full medication, a spasm provocation test was performed. In the RCA, intracoronary injection of $20 \mu \mathrm{g}$ ACh provoked total spasm at proximal RCA. Meanwhile, in the LCA, the injection of $100 \mu \mathrm{g}$ of ACh provoked diffuse spasms in both the distal LAD and proximal LCX artery. We judged that this medication would not be sufficient to suppress the next attack and switched from amlodipine $(5 \mathrm{mg}$ ) to benidipine 8 $\mathrm{mg} /$ day and increased the dose of the nitrates (nitrate tape: $40 \mathrm{mg} /$ day). The stimulated electrophysiological study was negative. The patient did not agree to implantation of an ICD device. After receiving these medications, his chest symptoms gradually improved and ultimately disappeared. Furthermore, under the above medications, including a statin, the patient complained of no chest pain for 126 months, without urgent admissions to the hospital.

\section{Case 5}

A 61-year-old man was transferred to the hospital because of severe chest oppression. He had a history of syncope of unknown cause two years ago and was a current smoker. Because VF had been observed in the ambulance, two cycle shocks by an automated external defibrillator recovered his VF. No ischemic ECG changes were found on admission. CAG was performed one week later, and no fixed stenosis was found. An ACh spasm provocation test was performed under no medication. An intracoronary injection of ACh 20 $\mu \mathrm{g}$ into the RCA provoked subtotal spasm at the proximal RCA, while proximal-LAD and LCX diffuse spasm was documented by the intracoronary injection of ACh $20 \mu \mathrm{g}$ into the LCA. Triple-vessel spasm was provoked by lowdose ACh administration accompanied by chest oppression and ischemic ECG changes. After the administration of medications including benidipine $8 \mathrm{mg}$ and isosorbide mononitrate $40 \mathrm{mg} /$ day for 7 days, triple-vessel spasm was also provoked by the single ACh test with chest oppression and ischemic ECG changes. Under sufficient medication, including benidipine $8 \mathrm{mg}$, ditiazem R $200 \mathrm{mg}$, isosobide mononitrate $40 \mathrm{mg}$, nicorandil $20 \mathrm{mg}$ and a statin, we reinvestigated the coronary response by the ACh test after 1 week. The intracoronary injection of ACh $50 \mu \mathrm{g}$ into the RCA disclosed distal RCA subtotal spasm, while both LAD and LCX proximal diffuse spasm was documented by the administration of ACh $50 \mu \mathrm{g}$ into the LCA. Ischemic ECG changes and chest oppression also recognized in both coronary arteries. We decided to implant an ICD because of refractory coronary spasm. Despite taking abundant medications, he was again transferred to another hospital due to syncope. At 15 months after ICD implantation, he died of pulseless electrical activity (PEA). His ICD showed no chocks and neither ventricular fibrillation nor tachycardia was recognized in the ambulance or at hospital admission.

\section{Results}

Under no medication, triple-vessel spasm was observed in four patients, and the remaining patient had multiple spasms, as shown in Table 2. We performed spasm provocation tests under medication to evaluate the effectiveness of medical therapy in five patients who had survived VF due to pure coronary spasm. Single ACh spasm provocation tests were performed in three patients, and sequential spasm provocation tests were underwent in two patients. ACh tests alone provoked typical spasm in two patients and did not provoke spasm in three patients. While ER tests alone provoked no spasm in two patients, the ACh added after ER test provoked single-vessel spasm in these patients. After the spasm provocation tests under medication, we strengthened medications to suppress coronary spasm. The mean number of vasodilators after the spasm provocation tests under medication were significantly higher than that in the initial diagnostic tests, as shown in Table 3. An ICD was implanted in two patients, including one with refractory spasm (case no. 5) and one with silent LMT spasm (case no. 2). One patient with ASCD due to refractory spasm died due to PEA but not VF.

\section{Discussion}

In this article, we described the results of spasm provocation tests under sufficient medication in five ASCD patients due to pure coronary spasm. We were able to strengthen the medications to suppress the next fatal events. However, one ASCD patient died due to PEA, but not VF. If we perform sequential spasm provocation tests to identify patients who require an ICD to suppress the next fatal ventricular arrythmia due to coronary spasm, we may be able to detect these high-risky patients earlier in the future. Because spasm provocation tests under medication may be useful for identifying patients who need an ICD to suppress the next fatal arrhythmic events, we may be able to use these tests to decide whether or not to implant an ICD in ASCD patients due to pure coronary spasm.

\section{Spasm provocation test under the sufficient medica- tions}

Spasm provocation tests were used to diagnose the presence of coronary artery spasm in the cardiac catheterization laboratory. According to the JCS guidelines, cessation of vasodilators for more than $48 \mathrm{~h}$ before pharmacological spasm provocation tests is needed for a strict diagnosis; however, we used this diagnostic method to clarify the actual vasospasticity under abundant medications in the clinic. In addition, we used sequential spasm provocation tests as 


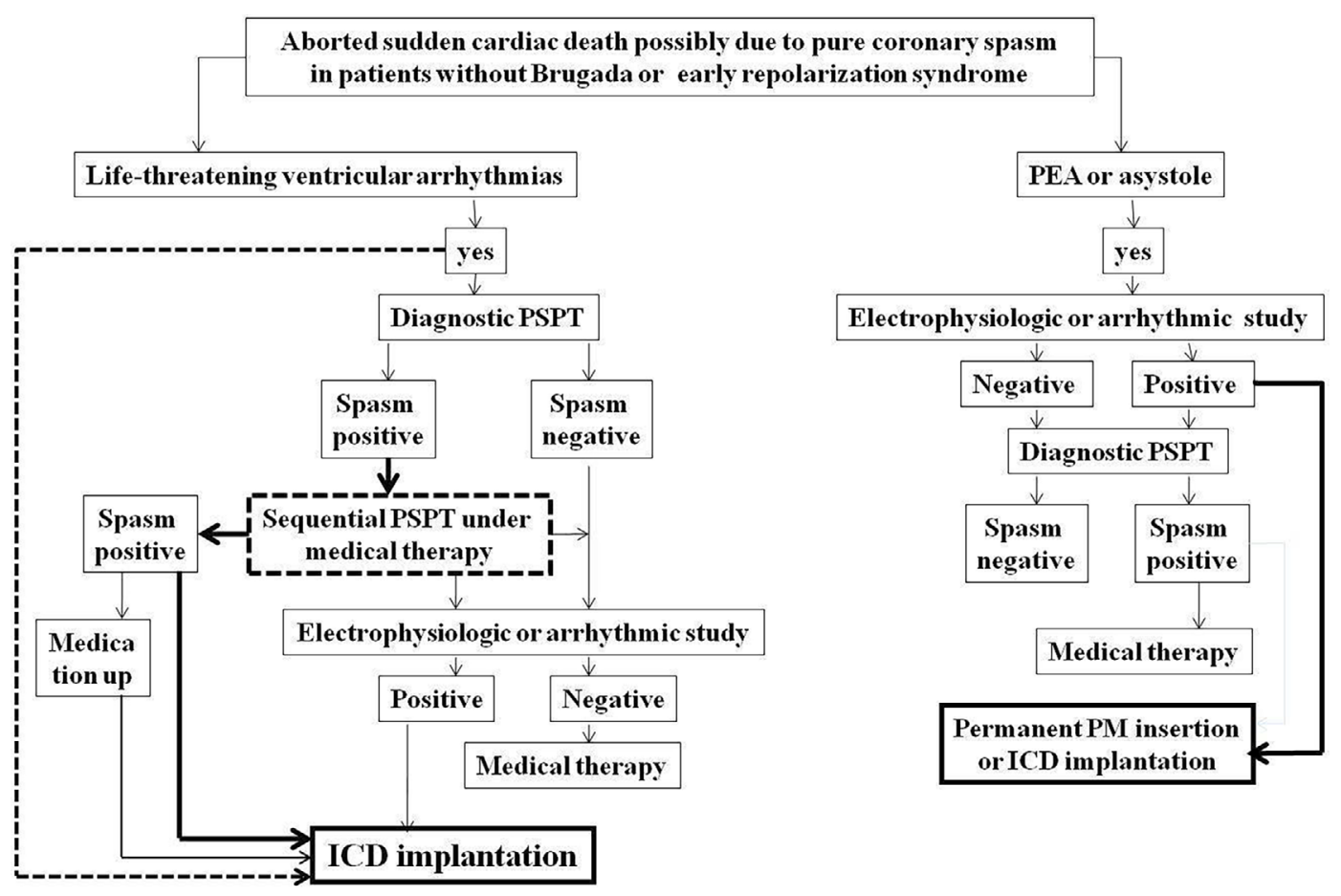

Figure 4. Schematic illustration of the strategy in patients with aborted sudden cardiac death due to pure coronary artery spasm and implantation of ICD. PSPT: pharmacological spasm provocation test, ICD: implantable cardioverter-defibrillator, PEA: pulseless electrical activity, PM: pacemaker

the most powerful spasm provocation test to ensure an excellent future outcome in ASCD patients due to coronary spasm. However, cardiologists normally do not use these tests to determine the effectiveness of medical therapy for suppressing the onset of the next fatal ventricular arrhythmias or for deciding on the need to implant an ICD. Medical therapy is the first-line therapy for patients with ASCD due to coronary spasm. Eschalier et al. recommended the ER tests be performed before the implantation of an ICD in patients with ASCD due to possible coronary spasm $(14,15)$. When ER tests were negative under optimum medical therapies, they recommended individual discussion for ICD implantation; if the ER tests were positive, they recommended ICD implantation in all cases, even if the optimum treatment was already being administered. If ASCD patients due to coronary spasm had spasm provoked by the sequential spasm provocation tests, cardiologists were advised to implant an ICD positively. However, when ASCD patients due to coronary artery spasm had no spasm provoked by the sequential spasm provocation tests, physicians were advised to medicate these patients without ICD.

\section{Strategy for patients with ASCD due to coronary ar- tery spasm without Brugada syndrome or early re- polarization syndrome}

We should also perform the electrophysiological or arrhythmic study in ASCD patients with pure coronary spasm. If the electrophysiological or arrhythmic study is positive, we should implant an ICD in these patents, as shown in Fig. 4. Some CSA cases are complicated with early repolari- zation or Brugada syndrome (16). These patients' prognosis are unfavorable compared to those of patients with pure CSA (17-19). We reported the findings of sequential spasm provocation tests in patients with refractory CSA under abundant medical therapies (13). If a provoked positive spasm is not noted on a sequential spasm provocation test under the optimal medical therapy in patients with ASCD due to coronary spasm, cardiologists and patients are free to select a course of medical treatment without ICD implantation, as shown in Fig. 4. However, if a single spasm provocation test, such as an ACh or ER test alone, shows a positive result under sufficient medical therapies, it may be better to implant an ICD. The indications of ICD insertion in patients with ASCD due to pure coronary artery spasm have not been established. As one option, we showed a schematic drawing of the strategy for ICD implantation in patients with ASCD due to pure coronary spasm using the sequential spasm provocation tests according to the medical therapy protocol shown in Fig. 5. If we performed the prospective sequential spasm provocation tests under sufficient medications in patients with ASCD due to coronary spasm in the future, we may be able to detect these patients who require an ICD to suppress the next fatal ventricular arrhythmia due to coronary spasm. Further studies will be necessary in order to investigate the implantation of ICD in patients with ASCD due to pure coronary spasm and further follow-up studies with the index regarding ASCD patients due to coronary spasm are needed as well. 


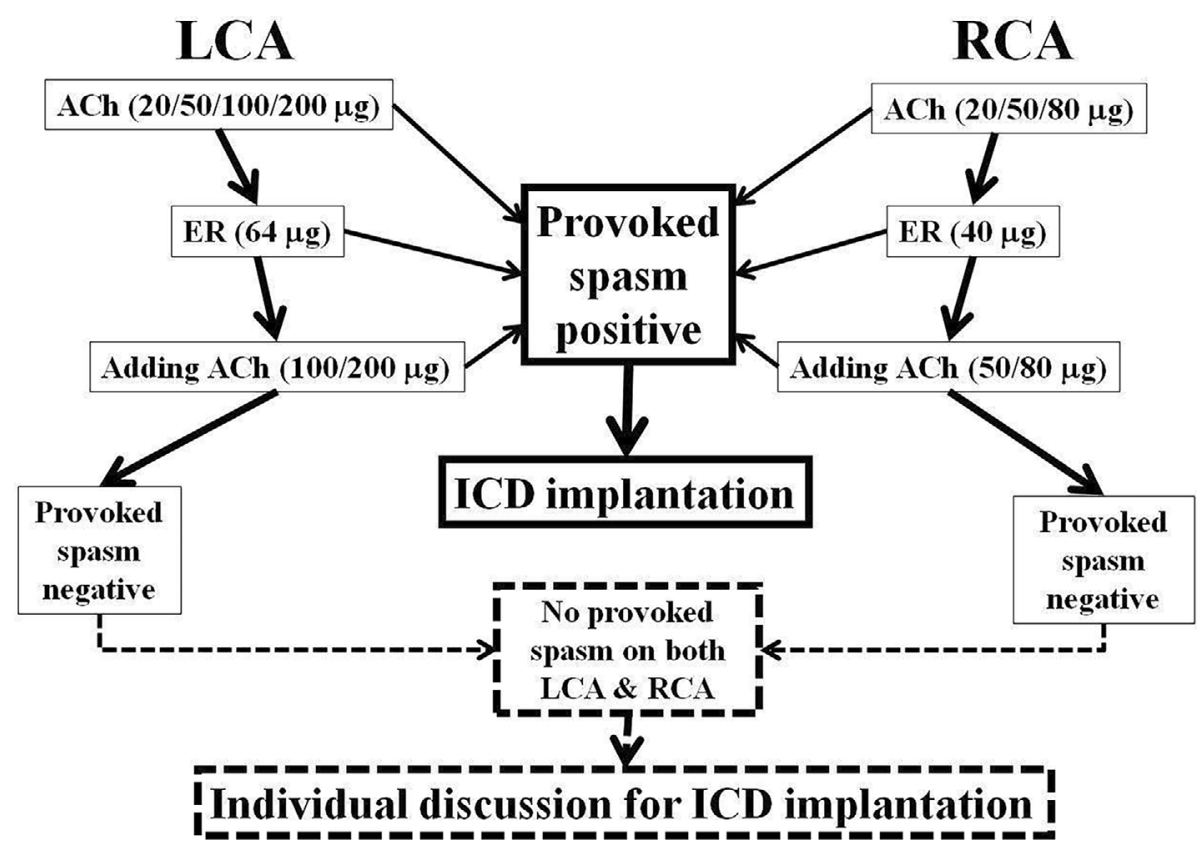

Figure 5. Schematic illustration of the strategy for ICD implantation in patients with aborted sudden cardiac death due to pure coronary spasm by the sequential spasm provocation test under medication. LCA: left coronary artery, RCA: right coronary artery, ACh: acetylcholine, ER: ergonovine, ICD: implantable cardioverter-defibrillator

\section{Conclusion}

By performing spasm provocation tests under sufficient medications in ASCD patient due to pure coronary spasm, we were able to strengthen the medical therapies. While one patient died of PEA (not VF), spasm provocation tests under medications remain a suitable option for deciding on medical or mechanical therapy in patients with ASCD due to pure coronary spasm.

\section{Limitations}

Several limitations associated with the present study warrant mention. We were only able to perform the spasm provocation tests under medications in just five of survivors VF due to pure coronary spasm. Furthermore, we were only able to perform sequential spasm provocation tests under medication in just two patients. Although we strengthened the medications after the spasm provocation tests, we lost one ASCD patient who had had an ICD implanted because of PEA.

The authors state that they have no Conflict of Interest (COI).

\section{References}

1. Yasue H, Horio Y, Nakamura N, et al. Induction of coronary artery spasm by acetylcholine in patients with variant angina: possible role of the parasympathetic nervous system in the pathogenesis of coronary artery spasm. Circulation 74: 955-963, 1986.

2. Okumura K, Yasue H, Matsuyama K, et al. Sensitivity and speci- ficity of intracoronary injection of acetylcholine for the induction of coronary artery spasm. J Am Coll Cardiol 12: 883-888, 1988.

3. Okumura K, Yasue H, Horio Y, et al. Multivessel coronary spasm in patients with variant angina: a study with intracoronary injection of acetylcholine. Circulation 77: 535-542, 1988.

4. Sato K, Kaikita K, Nakayama N, et al. Coronary vasomotor response to intracoronary acetylcholine injection, clinical features, and long-term prognosis in 873 consecutive patients with coronary spasm: analysis of a single-center study over 20 years. J Am Heart Assoc 2: e000227, 2013.

5. Ong P, Athabasiadis A, Borgulya G, Mahrholdt H, Kaski JC, Secctem U. High prevalence of a pathological reponse to acetylcholine testing in patients with stable angina pectoris and unobstructed coronary arteries: the ACOVA study. J Am Coll Cardiol 59: 655-662, 2012.

6. Zaya M, Mehta PK, Merz NB. Provocative testing for coronary reactivity and spasm. J Am Coll Cardiol 63: 103-109, 2014.

7. Sueda S, Ochi T, Yano K, et al. New combined spasm provocation test in patients with rest angina: intracoronary injection of acetylcholine after intracoronary administration of ergonovine. Jpn Circ J 64: 559-565, 2000.

8. Sueda S, Miyoshi T, Sasaki Y, Skaue T, Habara H, Kohno H. Sequential spasm provocation tests might overcome a limitation of the standard spasm provocation tests. Coron Artery Dis 26: 490494, 2015.

9. JCS joint, working group. Guidelines for diagnosis and treatment of patients with vasospastic angina (Coronary spastic angina) (JCS 2013). Circ J 78: 2779-2801, 2014.

10. Meisel SR, Mazur A, Chetboun I, et al. Usefulness of implantable cardioverter-defibrillator in refractory variant angina pectoris complicated by ventricular fibrillation in patients with angiographically normal coronary arteries. Am J Cardiol 89: 1114-1116, 2002.

11. Matsue Y, Suzuki M, Nishizaki M, Hojo R, Hashimoto Y, Sakurada H. Clinical implications of an implantable cardioveterdefibrillator in patients with vasospastic angina and lethal ventricular arrhythmia. J Am Coll Cardiol 60: 908-913, 2012. 
12. Sueda S, Fujimoto K, Sasaki Y, Nishimura K. Ventricular fibrillation survivor due to painless multiple spasm including left main trunk: is the subcutaneous implantable cardioverter-defibrillator necessary? J Cardiol Cases 20: 118-121, 2019.

13. Sueda S, Kohno H, Miyoshi T, Sasaki Y, Sakaue T, Habara H. Spasm provocation tests performed under medical therapy: A new approach for treating patients with refractory coronary spastic angina on emergency admission. Intern Med 53: 1739-1747, 2014.

14. Eschalier R, Souteyrand G, Jean F, et al. Should an implanted defibrillator be considered in patients with vasospastic angina? Arch Cardiovasc Dis 107: 42-47, 2014.

15. Eschalier R, Motreff P, Bordachar P. Risk of recurrence after life threatening ventricular arrhythmias in coronary spasm. Arch Cardivasc Dis 107: 205-206, 2014.

16. Fumimoto $T$, Ueyama $T$, Shimizu A, et al. Inferior $J$ waves in patients with vasospastic angina might be a risk factor for ventricular fibrillation. J Cardiol 70: 271-277, 2017.

17. Inamura Y, Nishizaki M, Shimizu M, et al. Early repolarization and positive T-wave alternans as risk markers for life-threatening arrhythmias in patients with vasospastic angina. Int J Cardiol 196: 7-13, 2015.

18. Oh CM, Oh J, Shin DH, et al. Early repolarization pattern predicts cardiac death and fatal arrhythmia in patients with vasospastic angina. Int J Cardiol 167: 1181-1187, 2013.

19. Komatsu M, Takahashi J, Fukuda K, et al. Usefulness of testing for coronary artery spasm and programmed ventricular stimulation in survivors of out-of-hospital cardiac arrest. Cir Arrhythm Electrophysiol 9: e003798, 2016.

The Internal Medicine is an Open Access journal distributed under the Creative Commons Attribution-NonCommercial-NoDerivatives 4.0 International License. To view the details of this license, please visit (https://creativecommons.org/licenses/ by-nc-nd/4.0/).

(C) 2020 The Japanese Society of Internal Medicine Intern Med 59: 1351-1359, 2020 